\title{
Uma Pessoa: Fernando «além do espelho»
}

\author{
ROBERTA ROSSI
}

This article recounts the origin and the artistic and philosophical presuppositions that make "UNA PERSONA. Ovvero come Fernando scoprì di essere stato Luigi", the ensemble performance which premiered at Napoli Teatro Festival in July 2020. The actor, with the artistic complicity of six musicians, weaves the weft of a poetic and musical journey through the multiplicity of the human being, expressed and recorded in the texts of Fernando Pessoa and Luigi Pirandello. The two were contemporaries, poetically alike but they never met; provocatively and ironically, we want to allude to the hypothesis that their physical encounter was never possible because the two had in fact been one person, the same person. On the set, conversing with the actor, is the music, the element which, through subtle hints, evocative melodies, original compositions and traditional songs, defines moods, emotions and every non-spoken sound which is portrayed in the life and the resonating, wonderful lyrics of the two writers.

PIRANDELLO / METATHEATRE / MUSiC / UNA PERSONA / PERFORMANCE

Em sua anormalidade, não pode ser senão amargamente cômica a condição de um homem que se encontra sempre fora de tom [fora da chave], por ser a um só tempo violino e contrabaixo; de um homem em quem não pode nascer um pensamento sem que imediatamente não lhe nasça um outro oposto, contrário: a quem por uma razão pela qual tenha de dizer sim, de pronto lhe surjam uma, duas, ou três que o obrigam a dizer não; e entre o sim e o não o mantenham suspenso, perplexo, por toda a vida.

LUIGI PIRANDELLO, O Humorismo

Teria estreado em Junho de 2020, por ocasião do prestigiado Napoli Teatro Festival, um espectáculo musical que desejei realizar ao longo de quase vinte anos.

O primeiro encontro entre Fernando Pessoa e Luigi Pirandello foi imaginado e contado por Antonio Tabucchi num singular monólogo, Il signor 


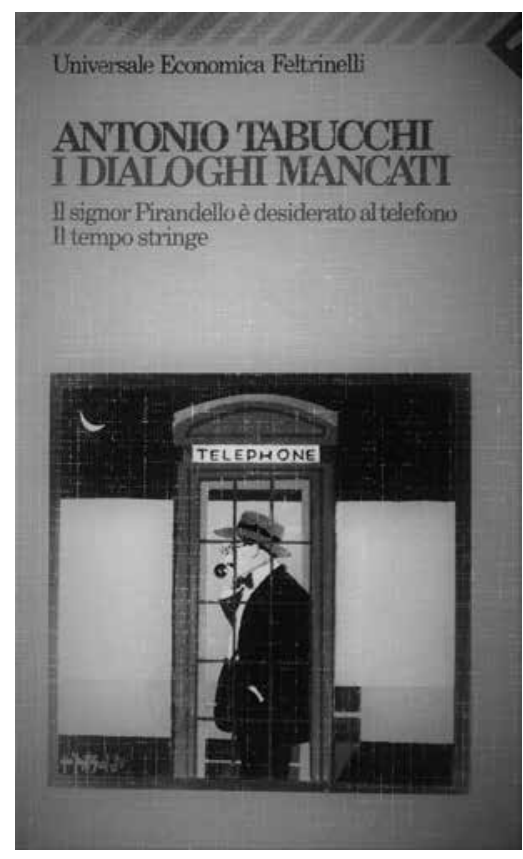

CAPA DE I DIALOGHI MANCATI, MILÃO, EDIZIONE UNIVERSALE ECONOMICA FELTRINELLI, 1995, ILUSTRAÇÃO DE JOSÉ BRITO CABINA TELEFONICA (NOTTE), TÊMPERA

Pirandello è desiderato al telefono, incluído num pequeno volume, I dialoghi mancati. Podemos ouvir somente uma voz, a de um Pessoa interpretado, visto ser implícito que a falar está um actor que interpreta Fernando Pessoa na solidão de um quarto de manicómio, numa imaginada chamada telefónica a Luigi Pirandello. Tudo é rarefeito, nada definido. A ideia que emerge é o desejo profundo de um diálogo, porém o elemento que mais se destaca seja talvez o silêncio do interlocutor (o escritor italiano).

Sabemos que Luigi Pirandello participou num congresso realizado em Portugal em 1931, o V Congresso Internacional de Crítica Dramática e Musical. Sobre isto conta-nos em pormenor Maria José de Lancastre no livro Con un sogno nel bagaglio. Un viaggio di Pirandello in Portogallo (Lancastre, 2006), texto no qual se faz, além do relatório desta viagem, uma análise comparativa do teatro dos dois escritores, em particular, entre Sogno (ma forse no), de Luigi Pirandello, e OMarinheiro, de Fernando Pessoa.

Teria sido, portanto, possível o encontro entre ambos. Mas tal não aconteceu. Podemos imaginar também que Pirandello não tivesse tido conhecimento da obra de Pessoa e, consequentemente, que a complexidade literária de tal envergadura posta em acto pelo poeta português, tão afim à poética e à filosofia do autor italiano, não excitasse alguma curiosidade em Pirandello. Permanece mais difícil imaginar que,

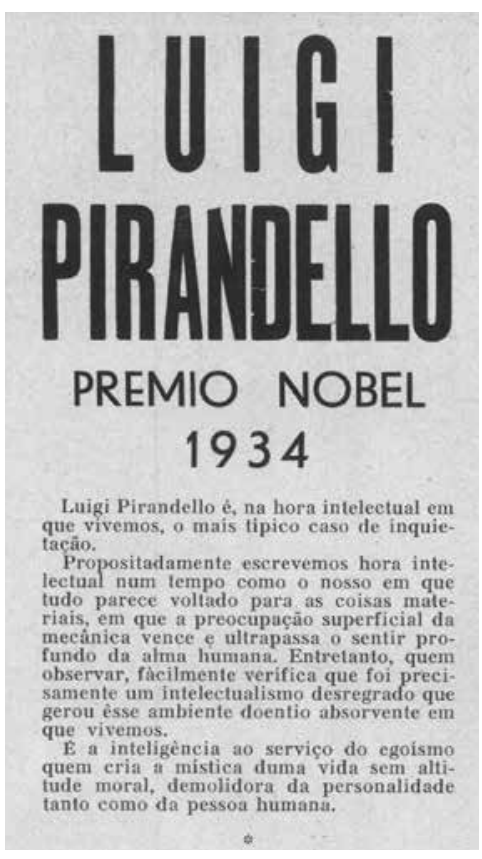

ESPÓLIO DE FERNANDO PESSOA, 135C-15A (PORMENOR)

vice-versa, Fernando Pessoa não tivesse conhecimento da literatura de Luigi Pirandello, que, naqueles anos, já havia escrito a maior parte das suas novelas e do seu teatro, conhecido na Europa e no mundo, e, pouco tempo depois, viria a receber o Prémio Nobel da Literatura.

Escreve Roberto Francavilla, num ensaio intitulado Sotto a questa realtà. Temas pessoanos nas novelas de Pirandello:

Em 1931, ano em que o semi-heterónimo Bernardo Soares escreve O livro do desassossego, Pirandello encontra-se em Lisboa para a estreia mundial de Sogno (ma forse no). Três anos depois, Pessoa dá ao prelo Mensagem, o único volume que publicou em vida, ao passo que Pirandello recebe o Prémio Nobel da Literatura. Em 1935, pouco antes de morrer, Pessoa redige a lápis as suas últimas palavras, em inglês, exprimindo uma lacónica interrogação sobre o enigma do além. No ano seguinte, também Pirandello morre. Nos seus últimos apontamentos, redigidos para a cenografia dramatúrgica, incompleta, de / Giganti della Montagna, lê-se: «c'è un olivo saraceno, grande, in mezzo alla scena: con cui ho risolto tutto». A solução tem, em si, algo de catártico, é um adeus consciente, como se a morte deixasse cair o pano, definitivamente, sem apelo nem agravo, sem hipótese de continuidade. (Francavilla, 2007) 
BANDARRA

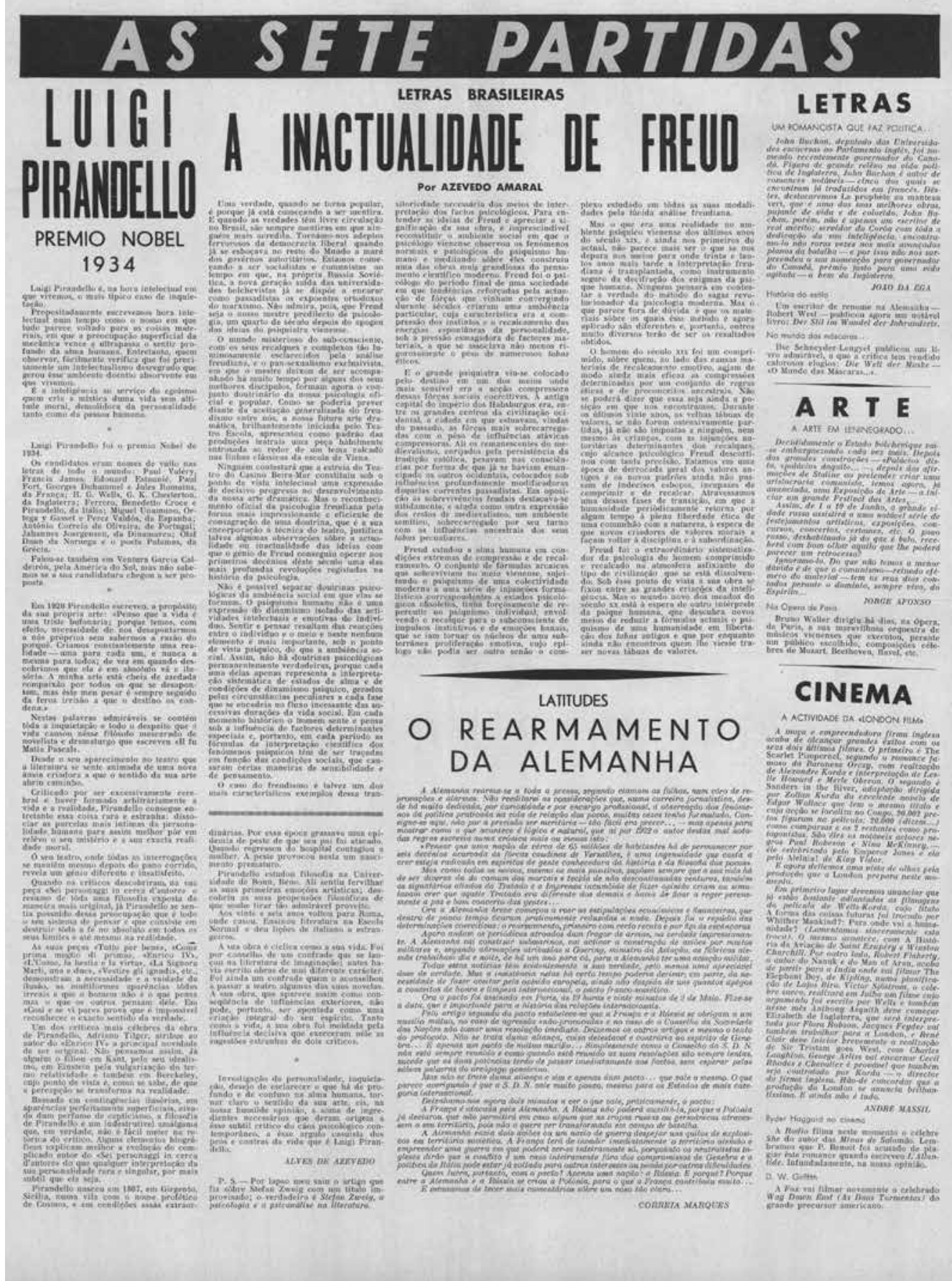

ESPÓLIO DE FERNANDO PESSOA, 135C-15A (PORMENOR)
Mas, não obstante a questão de um seu contacto real, de uma sua intersecção, de um seu confronto, ter sido amplamente abordada e debatida em investigação académica, tanto quanto sabemos, ambos jamais fizeram nem uma menção um ao outro.

E precisamente a partir da ausência de um contacto pode começar a tomar corpo o meu trabalho... a partir deste auscultador silencioso, deste «diálogo em falta», desta distância misteriosa por colmatar. A começar por uma sugestão, quase irónica e provocatória, que se torna pergunta: se os dois jamais tivessem podido encontrar-se, simplesmente porque ambos nunca existiram enquanto sujeitos separados? Se tivessem sido a mesma entidade literária? Se tivessem sido a mesma pessoa?

Fernando Pessoa, como um Homero contemporâneo, permite-nos uma grande especulação nesse sentido. A sua literatura é a encarnação da despersonalização, do desmembramento do $\mathrm{Eu}$, da desmancha da consciência que caracterizou todo o século $\mathrm{xx}$, a mesma literatura que gerou a crise da identidade do sujeito e, com esta, criou os pressupostos para o nascimento da psicanálise. Parece, nesta óptica, plausível imaginar que, desmanchando cada parte do ser em outras, também se possa acabar por não existir ou por existir em qualquer outra pessoa, em qualquer outra forma.

Luigi Pirandello funda o seu pensamento na relação dialéctica entre «vida» e «forma», entre aquilo que o ser humano é e aquilo que este pode representar para si ou para os outros. Evidencia o sentimento de subjugação do papel que as sociedades, com regras pré-constituídas, impõem ao ser autêntico que, na verdade, é mutável e jamais definido. Fala-nos, enfim, da «máscara» que vestimos, à procura desta definição, e de como a alma e o instinto podem desintegrá-la, pondo o indivíduo e o seu desmembramento no núcleo da questão poética e representando o profundo drama da reacção, ruinosa, do sujeito à sua própria máscara.

Assim, a multiplicidade do ser e o desmembramento da consciência fazem-nos mergulhar na mais desesperada das solidões, não a da Humanidade sozinha, mas a de uma Humanidade, ignorada até então, que não é, uma Humanidade estranha a si mesma. Partindo de «um» que cremos ser, num tornar-se contínuo somos «cem mil»e, portanto, não conseguindo determinarmos de modo algum, damos connosco a ser «ninguém». Ainda Roberto Francavilla:

Um e outro chegam às mesmas conclusões e acoutam as mesmas angústias, seguindo percursos individuais que tendem mesmo a frequentes 
intersecções. Aliás, a época está madura: impossível, de facto, não situar a sua linha epistemológica na reacção ao naturalismo, ao positivismo e ao determinismo que assinala a dobragem do século. [...] O axioma de acordo com o qual a consciência possui zonas que existem em estado latente e que, contudo, podem intervir alterando ou mesmo fragmentando o equilíbrio superficial da existência, é esteio do pensamento e das poéticas de ambos os escritores, levando-os a uma firme negação do reducionismo, ou seja, da tendência para estabelecer uma relação entre factos da psique e causas de natureza fisiológica; ao repúdio da pretensão de fragmentar a consciência em sensações desligadas, atomísticas; e, por consequência, a uma questão nodal (a qual, progressivamente, se vai tornando preponderante), a do inconsciente. (Francavilla, 2007)

Apaixonei-me pela escrita de Fernando Pessoa quando era pouco mais do que uma gaiata, teria, no máximo, uns quinze anos. Numa tarde de aborrecimento estivo, vasculhando na estante da minha tia, enquanto estava em casa da minha avó a passar férias, dei de caras com um livrinho minúsculo, arroxeado, com uma imagem magnética que soube, somente depois, tratar-se de Fischblut, de Gustav Klimt, que não conseguia deixar de admirar. O livro era $O$ Marinheiro, na tradução de Antonio Tabucchi. Ignorando tudo a respeito do caso Pessoa, pus-me a ler de uma assentada, intuí como prepotente o mistério que dele emanava, embora talvez não tivesse ainda a maturidade necessária para compreender em profundidade a obra... de qualquer modo, nela mergulhei e dela fui sugada como se do vórtice desenhado no quadro da capa. Sucessivamente comecei a ir atrás de todos os títulos disponíveis, em qualquer livraria em que metesse o pé, pois queria ler mais daquela literatura fascinante, obscura e vital ao mesmo tempo. Assim cresceu a minha paixão, a par da minha curiosidade, por este poeta tão precioso e único.

Luigi Pirandello, por sua vez, chegou, pouco depois, nas carteiras do liceu, suscitando-me de imediato grande simpatia e evocando com acutíssimo humorismo todo aquele pungente e muitíssimo complexo sistema filosófico que me fascinava tão profundamente; adorei-o com facilidade. $\mathrm{Na}$ adolescência, além disto, antes de escolher dedicar-me completamente à música (ainda que viesse a trabalhar, posteriormente, como intérprete musical em peças de teatro), participei em alguns laboratórios teatrais, podendo, assim, encontrar actores e encenadores entre os mais importantes e competentes no panorama do teatro italiano (Marco Martinelli, Claudio Di Palma, Laura Curino, etc.); tudo me suscitava curiosidade!

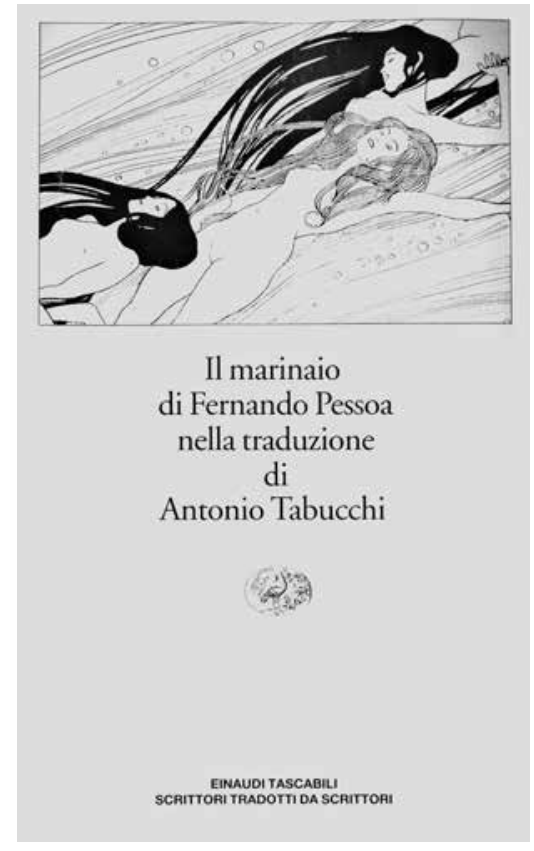
DE ANTONIO TABUCCHI. TURIM, EINAUDI, 1996. FISCHBLU, GUSTAV KLIMT, ILUSTRAÇÃo PARA A REVISTA VER SACRUM, MARÇO DE 1898

De saber, de ver, de ouvir e de conhecer tudo. Encontrei, entre os meus colegas de percurso, um rapaz ainda mais novo do que eu, indubitavelmente talentoso, com quem nasceu uma belíssima amizade. Ele, hoje, torna-se o meu «Fernando» em palco, Renato Avallone. Quase poderia dizer que Il Signor Pirandello è desiderato al telefono tenha sido o embrião deste trabalho e desta colaboração, pois, nos tempos da nossa juventude, queríamos pô-lo em cena juntos, tanto que chegámos a fazer alguns ensaios um pouco atrapalhados. Hoje, trabalhar com ele num projecto tão importante como este faz-me muito feliz, permite-me sentir poder realizar qualquer coisa que, à época, não passara de uma ideia e que permaneceu incompleta.

O paralelismo entre os dois escritores sempre me pareceu óbvio, tanto que escolhi contá-lo mediante uma selecção de palavras dos próprios autores. Com essas palavras, construí um monólogo intitulado Una Persona. Um único actor, portanto, em cena, atravessará um delírio de personalidade. Está empenhado em manter o fio condutor do discurso no fluir caótico dos seus pensamentos e a permanecer em equilíbrio nesse fio subtil, mas indissociável que liga o escutar de todas as vozes, heterónimas, que intervêm na orquestração deste monólogo delirante. São as próprias palavras que as animam, textos de excelsa poesia e, em simultâneo, de ingénua, corpórea, quotidiana realidade. Temperadas com 
um pensamento subtil, com uma leitura filosófica da existência, com a profundidade muito além da qual se incita o sentir poético de ambos os escritores.

$\mathrm{O}$ artigo indeterminativo contido no título deste espectáculo consente-nos a situar a universalidade desta história no centro da questão, visto não poder representar algo senão todos nós. Mas é também um artigo que determina, dando-lhe uma indicação numérica, uma quantidade. «Uma» só pessoa, logo, só e indeterminada, que pode tornar-se específica ou genérica. Todas as personalidades que debruçam o canto são específicas, visto conhecermos o seu autor, ao mesmo tempo, são genéricas, visto falarmos do drama de cada um de nós, a saber, não a nossa existência, mas sim a história do nosso existir.

Uma selecção de alguns dos momentos mais representativos de Uno, Nessuno e Centomila ${ }^{1}$ - o último romance de Luigi Pirandello, que, narrando as reflexões de um extremo processo interior da procura de si mesmo que levará o protagonista à loucura - é recitada pelo actor, tecendo-se uma malha única com alguns poemas de Alberto Caeiro, Álvaro de Campos, Ricardo Reis, algumas reflexões de Bernardo Soares, algumas falas de Fernando Pessoa ortónimo e, possibilitando o diálogo de temáticas, imagens, sonoridades poéticas e musicais, visões do ser e da realidade, constrói a teia narrativa na qual os elementos do conto se articulam.

Mas a narração dramatúrgica é confiada quase por inteiro à música. São as canções, as melodias, os instrumentos e os músicos a acompanhar as palavras, por meio de uma linguagem, de certa forma, mais imediata e eficaz à essência do seu significado. E é deste significado que a música se fará veículo e amplificador para chegar ao público. É um elemento em constante diálogo com a poesia dos textos.

À música, por outro lado, os dois poetas fazem frequentemente referências explícitas. Luigi Pirandello publica uma colectânea de poemas intitulada Fuori di chiave. ${ }^{2}$ Com a composição destas rimas, o poeta quer contar a parábola da vida de um homem, do nascimento ao declínio, e utiliza a metáfora da orquestra. «Este é o homem totalmente alienado da orquestra, que toca uma canção sua, destoada, tão fora de tom», escreveu Alice Serrão, terminando o prefácio à colectânea; mais ainda:

1 Publicado em 1926 por Bemporad, depois de uma gestação muito demorada e trabalhada, que se iniciou em 1909. Apareceu primeiro por capítulos na revista La Fiera letteraria, de Dezembro de 1925 a Junho de 1926.

2 Editore Formiggini, Genova, 1912. Alguns poemas da colectânea tinham sido anteriormente publicados em revistas como Riviera Ligure ou Nuove Antologie. o homem que emerge de Fuori di Chiave é portador da laceração que atravessa o século Xx. Um século acerca do qual a literatura procurou exprimir as fracturas e as rupturas com uma polifonia de vozes, à qual pertence também a de Pirandello [...] Pirandello aceita o desafio de uma estrada nova [...], tocando o seu mal-estar, como um instrumento da orquestra. (Serrão, 2013)

E Pessoa escreveu: «Minha alma é uma orquestra oculta; não sei que instrumentos tange e range, cordas e harpas, tímbales e tambores, dentro de mim. Só me conheço como sinfonia» (Pessoa, 1990: 128). Estes são os primeiros versos que a voz recitante nos faz ouvir, em voz off, enquanto a cena já é habitada por seis músicos e os seus instrumentos. Um grupo deliberadamente não conotado numa sonoridade específica da tradição popular - seja siciliana, seja portuguesa - mas decididamente moderno, que tenha modo de se exprimir numa linguagem pop (entendida como extracção cultural, logo, acessível a todos, a par daquela tradição), se bem que refinada e de cunho jazz, para poder contactar com o elemento de verdade do hodierno que permeia as vidas dos ouvintes.

Além de algumas composições de Andrea Bonioli e minhas, escritas para este espectáculo, pedi emprestadas à tradição portuguesa e à siciliana algumas das melodias mais representativas da memória cultural dos dois lugares, «Tudo isto é fado» (numa versão, arranjada para a ocasião, que a sobrepõe a uma canção de tradição napolitana, «Torna a Surriento», muito semelhante na harmonia e sabor) que trazemos no coração e nos ouvidos pela voz de Amália Rodrigues, e «Vitti Na Crozza» (uma revisitação em chave jazz de um tema siciliano com uma história de paternidade incerta, mas entre os mais conhecidos e cantados no mundo, interpretada, além do mais, pela mesma Rodrigues). Escolhi utilizar também temas contemporâneos de artistas e compositores, neste caso compositoras, que falam sobre e praticam a sua música ao tornarem-na actual por meio da tradição. É o caso de «A mulher vento», de Carminho, e «Malamuri», de Olivia Sellerio.

Boa parte das canções é em língua italiana, língua na qual se exprime também o nosso protagonista (o actor), língua na qual escrevo as minhas canções. Uma destas é retirada do meu primeiro disco, Nuove Forme 3 , e contém um texto inspirado num passo poético de Fernando Pessoa, da qual cito aqui alguns versos: «Tante cose, tante cose.../ Tante cose e mani.../

3 Nuove Forme de Variable Timeline. Publicado por Full Heads em 2013. Distribuição Audioglobe. 


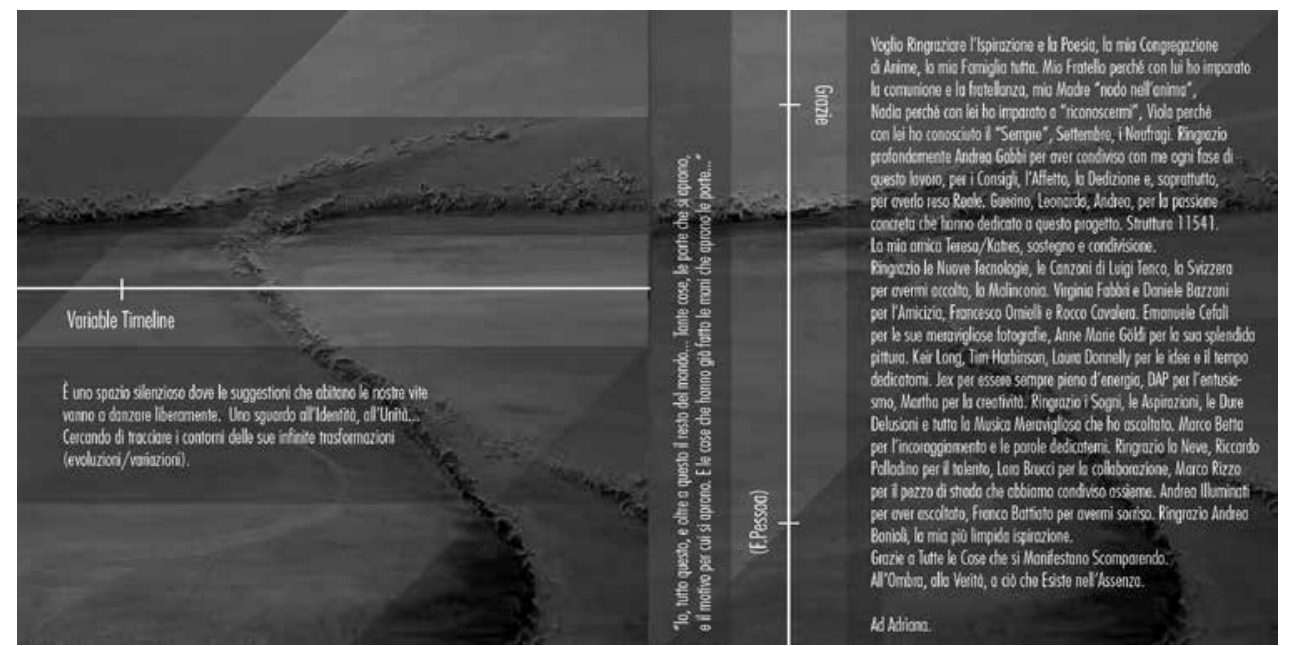

PLANO DE IMPRESSÃO PARA O ENCARTE DO CD NUOVE FORME (ALBUM DE VARIABLE TIMELINE - ROBERTA ROSSI), DESIGN GRÁFICO DE MARTHA TER HORST

Tante cose, tante cose.../ Tante porte, tante mani.../ Scivolando sulle cose perchésia domani,/ provenendo dall'altrove verso il mio domani». ${ }^{4}$ Quer-se invocar os versos: «Eu, tudo isto, e além disto o resto do mundo.../ Tanta coisa, as portas que se abrem, e a razão por que elas se abrem,/ E as coisas que já fizeram as mãos que abrem as portas...» (Pessoa, 1993b). Esta frase sempre me apelou a grandes cenários metafísicos. Percepciono o fio que une todos os eventos da existência confluir numa autodeterminação da vida. Um motor vital, de amor à vida, que nos permite abrir, num ciclo infinito, sempre novas portas, novas possibilidades, novos horizontes, não obstante o peso da matéria e da forma nos façam sempre prisioneiros das razões por que isto continua a acontecer.

Os outros meus dois temas inseridos no repertório são, ao invés, ainda inéditos; serão apresentados pela primeira vez ao público quando subirmos ao palco. Além desses, incluí alguns temas de autores como Ivano Fossati («La mia giovinezza»), e como Franco Battiato, artista por que nutro particular carinho. De Battiato escolhi uma tradução em língua italiana de uma canção de Anthony Hegartys, «Del Suo Veloce Volo». Servir-me-á para descrever, de modo delicadíssimo, uma relação amigável e profunda entre duas almas que jamais poderão encontrar-se;

Verso il mio domani, de Roberta Rossi, apresenta uma referência explícita a alguns versos de «Passagem das Horas», a ode sensacionista de Álvaro de Campos.

5 Antony and the Johnsons são uma banda norte-americana liderada por Anthony Hegarty. O tema, na sua versão original, intitula-se «Frankenstein». por isso, foi inserida num momento em que a história revela ao espectador alguns aspectos da relação muitíssimo peculiar entre Fernando Pessoa e Álvaro de Campos, com curiosidades que dizem respeito à sua relação com Ofélia Queirós.

Senti a necessidade de inserir ainda no repertório um tema em língua inglesa, língua quase materna de Fernando Pessoa, que passou boa parte da sua infância e adolescência na África do Sul, e de aproximá-lo ao momento extraído de «Passagem das Horas», que, nesta representação, assume quase as feições de um cântico para os últimos da terra. O tema é «Tomorrow is my Turn» de Nina Simone, e é acompanhado por imagens de pessoas sós, povos de migrantes em fuga dos infernos terrestres, imagens de desespero (as únicas imagens projectadas não pertencentes ao portefólio de Maurizio Sacco) a representarem uma possibilidade, a mesma oferecida pelas palavras do poeta, neste caso Álvaro de Campos, ou seja, que «Tudo é razão de ser da minha vida» (Pessoa, 1993b). Quero contar assim a esperança que esta humanidade, obrigada a desumanizar-se, possa reconhecer-se e reencontrar-se num profundo sentir comum e reconstruir-se, tendo bem presente que este é um ciclo infinito e indeterminado no tempo.

Seria preciso um pouco mais de entendimento entre o homem e a natureza. Com muita frequência a natureza se diverte jogando ao ar todas as nossas engenhosas construções. Ciclones, terremotos... Mas o homem não se dá por vencido. Reconstrói, reconstrói, bichinho insistente. E tudo é para ele matéria de reconstrução. Porque tem em si aquela tal coisa que não se sabe o que é, pela qual deve forçosamente construir, transformar a seu modo a matéria que lhe oferece a natureza ignara, talvez, e pelo menos quando quer, paciente. Mas devia se contentar somente com as coisas que, até prova em contrário, não se saiba ter em si a faculdade de se sentirem torturadas por causa de nossas adaptações e nossas construções! Não senhores. O homem também pega a si mesmo como matéria, e se constrói, sim senhores, como uma casa. (Pirandello, 2019)

Sempre pensei que os textos, seja de Pessoa, seja de Pirandello, transbordassem de atitude positiva, visto serem plenos de vitalidade, daquela «verdade/ [q]ue uma flor tem ao florescer» (no dizer de Caeiro; cf. Pessoa, 1993a), daquela simplicidade que somente o valor mais amplo, transversal e alto pode permitir a si mesmo de exprimir. Por esta razão, talvez, neste trabalho vejo a fusão e a indeterminação dos seres na sua acepção 


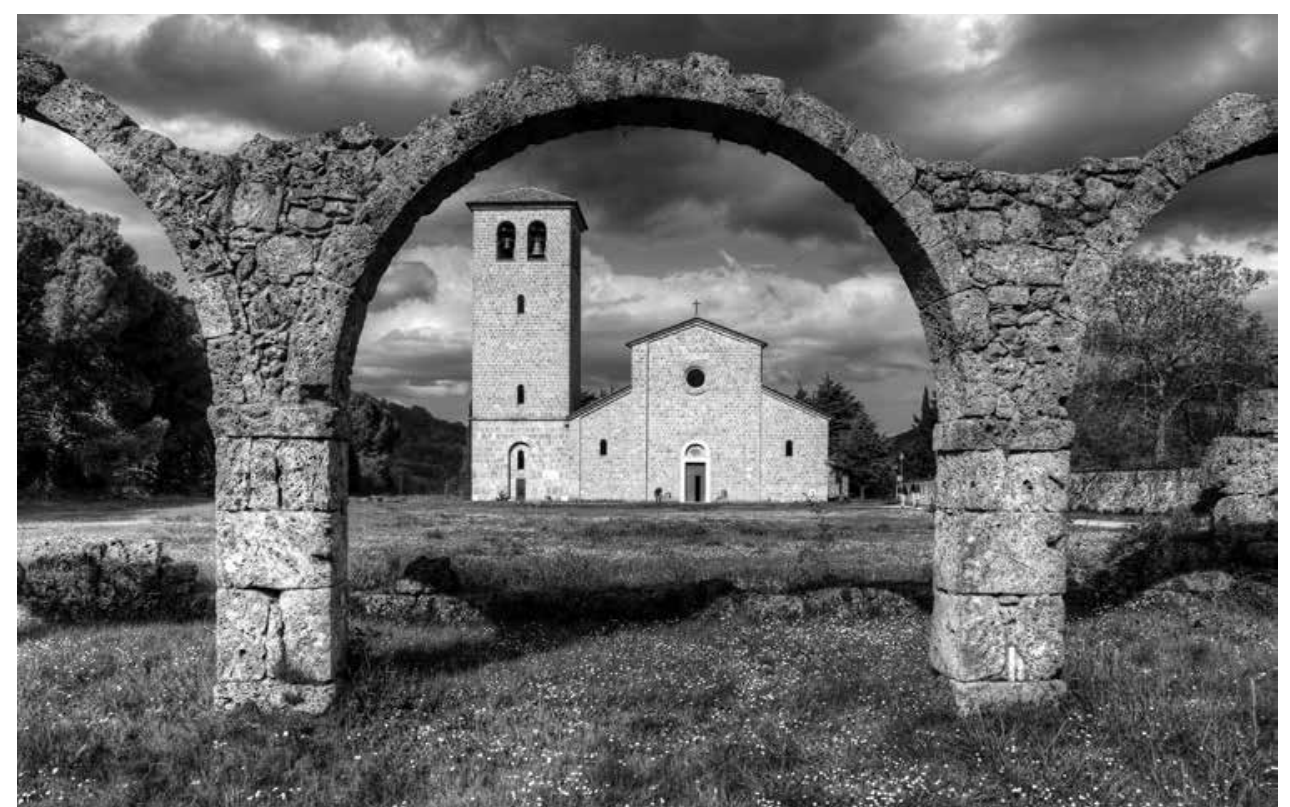

ABADIA de SAN VINCENZO AL VoltURNo - CASTEL SAN VINCENZO (ISERNIA, ITÁLIA), LF] MAURIZIO SACCO

positiva, como uma forma de esperança, uma via de reconciliação connosco mesmos e com o outro, em ausência total de juízo e tentativas falhadas de definição. Em O Guardador de Rebanhos, Caeiro escreve: «os seres existem e mais nada,/ e por isso se chamam seres» e ainda, «que não há mistério no mundo/ e que tudo vale a pena» (Pessoa, 1993a). São palavras que parecem suspender o juízo em favor da lógica do sentir e eliminar a separação em favor da comunhão com a existência.

Seis músicos em cena com os seus instrumentos: um piano, tocado por Emiliano Begni; um contrabaixo, tocado por Andrea Colella; uma bateria, atrás da qual se senta Andrea Bonioli, compositor de algumas das canções originais do espectáculo, como, por exemplo, «Fernando», tema que, entre os vincos da voz que recita, regressará para nos recordar aquele núcleo prepotente (insistente na sua reconfortante melancolia), a forma que acreditamos ser e não somos; um clarinete e uma viola clássica, respectivamente Michele Villari e Alessio Toro, guiados por uma voz que canta, Roberta Rossi, e por um actor, prisioneiro das suas contínuas metamorfoses, Renato Avallone. Emoldurados pelas projecções, com valência cénica na maior parte das vezes, de algumas das mais belas fotografias de um jovem e talentoso fotógrafo italiano, Maurizio Sacco.

A cena é pobre, não há objectos, nem estruturas cénicas, nem cortinas visíveis. Há somente pessoas, engolidas por imagens e nomes, que

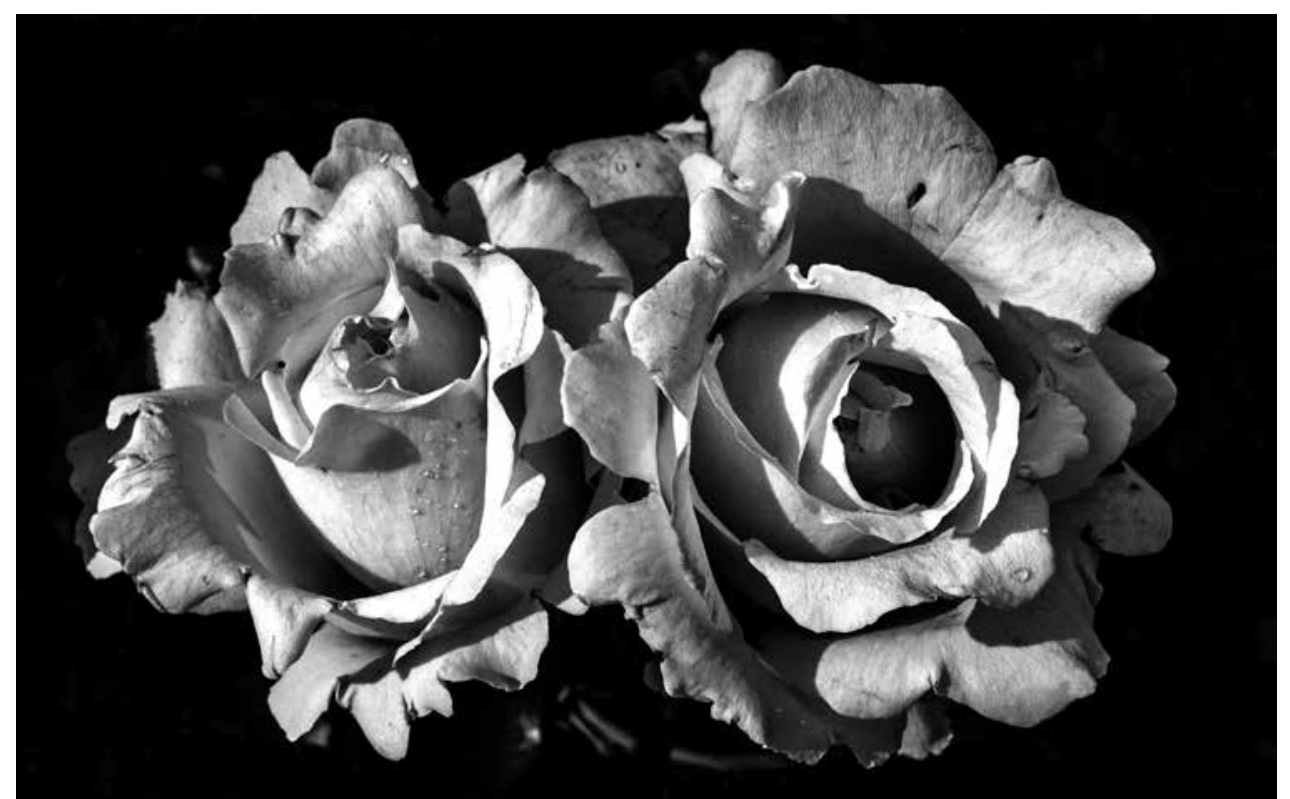

INFINITY, [F] MAURIZIO SACCO

traduzem em som o sentido e, por meio deste, o filtram. É um concerto de almas. A cena representa a mente, e as pessoas que actuam em palco simbolizam as múltiplas identidades que a habitam. Ainda que disto sejam apenas uma minúscula amostra, exprimem, com a sua forma e a sua presença no espaço cénico, uma densidade de matéria que delineia os traços das suas personalidades.

Para guiar o espectador no percurso que se delineia por meio das palavras das múltiplas identidades narradoras e até que a sinfonia destas palavras de poesia possa ser usufruída como testemunha de uma verdade entendida e, portanto, vivida, logo real (e não apenas como itinerário através das possibilidades infinitas e indefinidas da personalidade do sujeito), por vezes no ecrã aparecem nomes próprios de pessoas, alternados com as fotografias. Sabemos que cada nome pertence à voz que está a actuar naquele preciso momento, mas jamais surgirão apelidos, elemento distintivo de uma especificidade que não nos é dada a conhecer e, nos finais da história do fluir do ser, não nos importam, na verdade, muito.

Todos os elementos representam entidades narrativas. Cada som, cada imagem, cada palavra participam na composição daquele momento teatral no qual vivenciamos a possibilidade de encontrar aquele espaço indefinido de existência que somos, sem máscaras e, sobretudo, sem a necessidade de nos definirmos numa qualquer forma identitária, para 


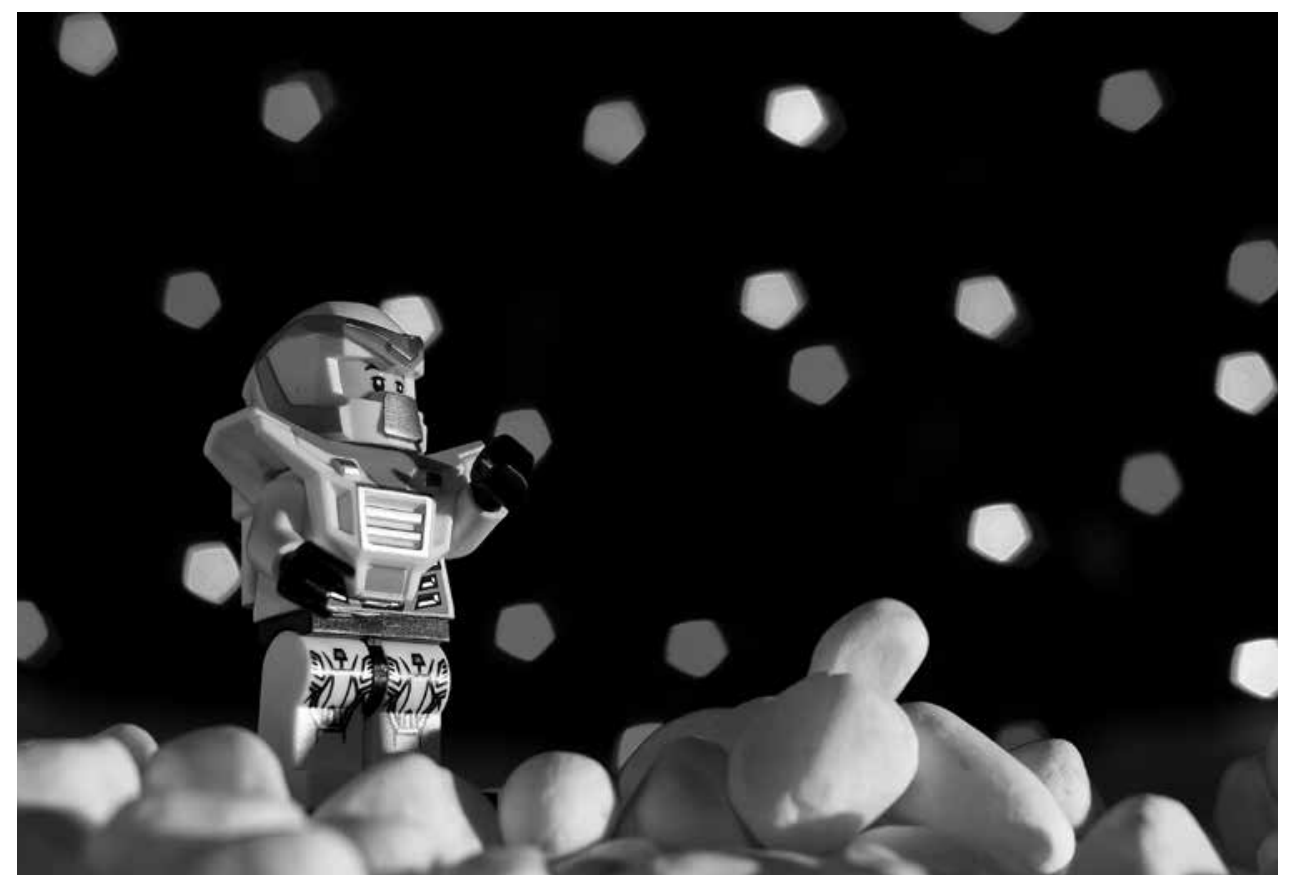

STARMAN, [F] MAURIZIO SACCO

«sentir tudo de todas as maneiras,/ viver tudo de todos os lados,/ ser a mesma coisa de todos os modos possíveis ao mesmo tempo,/ realizar em si toda a humanidade de todos os momentos/ num só momento difuso, profuso, completo e longínquo» (Pessoa, 1993b).

Nestes versos, colho a intersecção do sentimento poético de Fernando Pessoa - tal como do pensamento de Luigi Pirandello - com tudo o que as descobertas da física moderna estavam a trazer à luz, durante os anos em que ambos os autores viveram, e que muito viriam a alterar a concepção da realidade, influenciando inevitavelmente todos os campos da filosofia e da arte e, não menos (ainda que muito mais lentamente), a vida quotidiana.

No seu $O$ Tao da Física, livro de que gostei muito pela sua ampla visão da interdisciplinaridade e da interculturalidade aplicadas a uma disciplina (frequentemente tida como rígida, mas, pelo contrário, surpreendentemente visionária) como a física, Fritjof Capra (físico americano, conhecido pelas suas publicações técnicas e pelos seus estudos sobre as implicações filosóficas da ciência moderna) mostra-nos as relações entre as novidades que se manifestaram graças à investigação em mecânica quântica e as filosofias orientais, tendo aproximado alguns dos métodos de ambas as disciplinas, ao relacionar a observação científica com a observação meditativa. Escreve:

As primeiras três décadas do nosso século modificaram radicalmente todo o panorama na física. Dois desenvolvimentos diferentes - o da teoria da relatividade e o da física atómica - destruíram todos os principais conceitos da visão newtoniana do mundo: a noção de espaço e de tempo absolutos, as partículas sólidas elementares, a natureza estritamente causal dos fenómenos físicos, e o ideal de uma descrição objectiva da natureza. [...] De acordo com a teoria da relatividade, o espaço não é tridimensional, e o tempo não é uma entidade separada. Ambos estão intimamente ligados e formam um contínuo a quatro dimensões, o «espaço-tempo». $\mathrm{Na}$ teoria da relatividade, portanto, nunca podemos falar do espaço sem falar acerca do tempo, como no modelo newtoniano. [...] Quer o espaço quer o tempo passaram a ser meros elementos da linguagem que um observador particular usa para descrever os fenómenos observados. [...] A consequência mais importante desta modificação é o entendimento de que massa não é mais que uma forma de energia. (Capra, 1989: 55-57)

Esta leitura levou-me a fazer profundas reflexões existenciais: comecei a compreender que a matéria, o mundo em que tocamos, aquilo que também nas convenções sociais tinha permanecido como a nossa última certeza, muda debaixo do nosso nariz e, escapando-se das mãos ao tornar-se informe, manifesta-se como concentração de energia. Nesta óptica, podemos compreender que também o invisivel tem uma sua materialidade. E a totalidade das coisas que existem e não existem, interpenetrando-se, interferem e comunicam entre si numa totalidade pânica ${ }^{6}$ semelhante em cada coisa aos cenários de descrição da realidade dos místicos orientais.

Um outro fenómeno relevante nos estudos de física moderna é o comportamento da luz. Escreve ainda Capra:

As unidades subatómicas de matéria são entidades abstractas que têm um duplo aspecto. Dependendo de como as perspectivamos, aparecem por vezes como partículas, outras como ondas; e esta natureza dupla é

6 Adjectivo - derivante do nome do deus grego חáv - que remete para uma visão da natureza concebida como força vital e criadora (de forma panteistica, justamente). Tal visão identifica a divindade com o mundo e ao mesmo tempo considera como divinas todas as coisas. 
também exibida pela luz, que pode tomar a forma de ondas electromagnéticas ou de partículas. [...] o observador humano constitui o elo final na cadeia dos processos de observação e as propriedades de qualquer objecto atómico só podem ser entendidas nos termos da interacção do objecto com o observador. Isto significa que a ideia clássica de uma descrição objectiva da natureza deixa de ser válida. (idem, 60-61)

É o observador, pois, a determinar a qualidade do fenómeno observado. A questão da perspectiva e do olhar assume uma credibilidade totalmente nova: o olhar é activo e em diálogo com a realidade.

«Tenho a alma rachada sob o indicador curvo que lhe toca» (Pessoa, 1914), escreve Pessoa na sua «Ode sensacionista», uma alma, portanto, pesada e que parece recordar-nos uma massa, uma concentração de emoção que transborda, aquele «espaço-tempo» encurvado pela força de gravidade de que Einstein nos ofereceu a visão e que modificou para sempre o modo de contar a nossa existência.

Em cena é evocado com frequência (porém, jamais aparecendo) o espelho, assumindo a função de um conceito, mais do que de um objecto. Um momento nodal do romance de Pirandello a que nos referimos é, sem dúvida, o diálogo entre Moscarda e o seu «estranho», que, na verdade, é ele próprio, em frente a um espelho. Vitangelo deseja «ardentemente» ficar sozinho em casa para procurar vestígios do seu interior desconhecido (que ainda crê ser «um só»). E o espelho será, com efeito, o seu instrumento de busca:

Antes quis me recompor, esperar que desaparecessem do meu rosto qualquer traço de ansiedade e de alegria e que, por dentro, arrefecesse qualquer sentimento e preocupação, de modo que pudesse levar para diante do espelho o meu corpo como estranho a mim e, como tal, enfrentá-lo. [...] Fui, com os olhos fechados, mãos à frente, tateando. Quando toquei o espelho do armário resisti esperando, ainda com os olhos fechados, a mais absoluta calma interior, a mais absoluta indiferença. Mas uma maldita voz me dizia por dentro que ele também estava lá, o estranho, na minha frente no espelho. À espera como eu, com os olhos fechados. Estava, e eu não o via. Ele também não me via, porque estava, como eu, com os olhos fechados. Mas ele estava à espera de quê? De me ver? Não. Ele podia ser visto; não podia me ver. Era para mim o que eu era para os outros, que podia ser visto e não podia me ver. Porém, se eu abrisse os olhos, eu o teria visto assim como um outro? (Pirandello, 2019)
Deste ponto de partida se desenrolará todo o processo resultante destas reflexões e destas buscas levadas a cabo pelo nosso Vitangelo ${ }^{7}$, que o levam à loucura, ou melhor, àquilo que convencionalmente se entende por tal, destruindo certamente todas as convenções sociais que mantinham de pé a sua vida e deixando-o na incompletude do ser. Dirá:

Nunca mais me olhei em um espelho, e nem me passa pela cabeça querer saber o que aconteceu com meu rosto e com toda a minha aparência. A aparência que eu tinha para os outros devia parecer muito mudada e de maneira muito divertida, a julgar pelo espanto e pelas risadas com que me receberam. No entanto, todos ainda me chamavam de Moscarda, apesar de Moscarda certamente já ter um significado diferente de antes para cada um, tanto que poderia ser poupada àquele pobre amalucado lá, barbudo e sorridente, com os tamancos e o camisolão azul, a pena de obrigá-lo a ainda atender àquele nome, como se realmente the pertencesse. Nenhum nome. Nenhuma recordação, hoje, do nome de ontem; do nome de hoje, amanhã. Se o nome é a coisa, se um nome é em nós o conceito de tudo o que está fora de nós, e sem nome não se tem o conceito, e a coisa fica em nós como cega, não distinta e não definida, então, que este nome que carreguei entre os homens, cada um o entalhe, epígrafe funerária, na fronte da imagem que vê de mim, e a deixe em paz não falando mais dela. Um nome é apenas isso, epígrafe funerária. Convém aos mortos. Para quem concluiu. Eu estou vivo e não concluí. $A$ vida não tem conclusão. $E$ a vida não conhece nomes. Esta árvore, respiro trêmulo de folhas novas. Eu sou esta árvore. Árvore, nuvem: amanhã livro ou vento, o livro que leio, o vento que bebo. Tudo fora, errante. (Pirandello, 2019)

O romance é narrado na primeira pessoa e o protagonista dirige-se constantemente a interlocutores, tornando a fórmula narrativa extremamente teatral. De resto, Pirandello desenvolveu e representou, por meio da escrita teatral, uma boa parte da sua poética, jogando muitas vezes, entre outras coisas, com os conceitos de «realidade»e «fingimento», tão caros à arte de qualquer sua declinação, mas certamente basilar no pensamento, tanto de Pirandello como de Fernando Pessoa.

7 Doravante, os apelidos das personagens cujas identidades aparecem em cena serão omitidos a fim de facilitar a identificação do leitor com eles, tal como desejamos aconteça aos espectadores no teatro. 
O poeta é um fingidor

Finge tão completamente

Que chega a fingir que é dor

A dor que deveras sente.

E os que lêem o que escreve,

Na dor lida sentem bem,

Não as duas que ele teve,

Mas só a que eles não têm.

E assim nas calhas de roda

Gira, a entreter a razão,

Esse comboio de corda

Que se chama coração.

(Pessoa, 1942)

A linha entre aquilo que representamos e aquilo que sentimos é muito mais subtil do que a nossa razão imagina e tanto a poesia pessoana como o teatro pirandelliano disso são um grande testemunho. Luigi Pirandello desmanchará as convenções, muito mais do que sociais, artísticas; verá os actores descerem até à plateia e trará o público para o interior do drama, encenando um fingimento declarado que fala de realidade ao espectador, na qual este poderá reconhecer-se através de uma verdade evocada pelo desmascaramento do fingimento. O próprio Pirandello o definiu «teatro no teatro».

Na minha representação, o espelho será substituído pela quarta parede que Pirandello decidiu abater com o seu metateatro. Será o símbolo da universalidade deste percurso de busca no qual cada um de nós se mede quotidianamente, será o instrumento que nos permitirá olhar para nós mesmos e reconhecermo-nos ou desconhecermo-nos, identificarmo-nos em algo que vemos além do espelho, ou ultrapassá-lo em direcção a uma nova possível expressão da nossa própria vida. Recita Bernardo:

Não consegui nunca ver-me de fora. Não há espelho que nos dê a nós como foras, porque não há espelho que nos tire de nós mesmos. Era precisa outra alma, outra colocação do olhar e do pensar. [...] queira o que queira, grave-se o que de mim se grave, estou sempre aqui dentro, na quinta de muros altos da minha consciência de mim. (Pessoa, 1982)
Admirar, portanto, a nossa imagem reflectida não nos capacita de nos separarmos daquilo que somos. Além do espelho, viramos inevitavelmente o olhar em direcção ao interior. Uma vez mais, é o observador quem incide na qualidade da realidade e, assim, o olhar do espectador na cena deveria remeter-nos à única verdade a que temos acesso: a verdade daquilo que sentimos.

Se, olhando ao espelho (que devolve uma realidade invertida e é, por isso, um outro elemento de perversão), «Fernando» tivesse visto «Luigi», em vez de si mesmo? Não teria sido algo senão uma das inumeráveis formas das quais se serviu para se manifestar, para ser. Se, olhando o palco, o público pudesse ver-se na cena? Se, graças à função catártica típica da experiência teatral, pudesse sentir os próprios sentimentos e as próprias emoções tomarem forma, como numa dança sem dançarino, nos sentimentos de Bernardo, nos pensamentos de Vitangelo, nas emoções de Álvaro ou de Ofélia? Se conseguíssemos despir-nos de todas as falsas certezas sobre nós próprios e conseguíssemos receber o que vemos reflectido, sem juízo? Poderemos iniciar, talvez, a procurar-nos e a contar-nos uma verdade que tanto nos aterroriza: que somos nada e cada coisa e somos forçados a fluir para ser, sem certeza alguma, desde os séculos dos séculos.

Nestes últimos dias, tivemos notícia de que o Festival quereria corajosamente abrir as portas ao público já no mês de Julho, com óbvias restrições e determinadas disposições sanitárias a respeitar. Confesso ter tido, ao receber esta notícia, muitas dúvidas sobre como poder subir a um palco num momento do género. A situação que o mundo inteiro atravessa (refiro-me obviamente à pandemia de covid-19) e que travou qualquer actividade artística e social como primeiro exercício, imagino que deixará uma longa repercussão de desconfiança e medo nos corações das pessoas.

Deixando de lado as questões técnicas - toda a instalação que permite a uma companhia ou a uma banda pôr em cena um trabalho, feito de ensaios, encontros e mudanças até agora completamente impossíveis de realizar-, fica o facto de que precisaremos de muito tempo para conseguir reconsiderar o papel que as artes performativas têm nas nossas vidas, para nos reapropriarmos dos lugares e dos espaços nos quais se consagra a troca, indispensável à vida e à sua narração, e experimentar a liberdade do contacto, seja concreto, seja figurativo, que é necessário a tal troca.

É verdade que talvez os artistas venham a ser capazes de inventar e sugerir uma nova chave de leitura da realidade: no fim de contas, é uma 
prática a que estão habituados, a traços também condenados. Sinto, pois, que a nossa presença em cartaz é profundamente útil para levar uma mensagem de esperança, um sinal de recuperação, uma visão para o futuro (ainda que incerto, mas a isso estamos, desde sempre, preparados por definição!).

Em simultâneo não podemos esquecer quão importante seja, para nós e para a arte, o público, o ouvinte, o usufruidor. Não para receber feedback ou simples gratificação, mas como componente inegavelmente activa, porque o olhar sobre uma obra é elemento interferente com a obra, porque o observador actua em cena, tal como na realidade quântica, porque o campo magnético do lugar da representação vive das energias de cada elemento individual que o compõe.

Portanto, lá estaremos. Iremos à cena. E então, fluiremos, todos juntos, nos finais de Julho.

Artigo traduzido do italiano por André Oliveira Baptista e Isabella Mangani

\section{ROBERTA ROSSI}

-

Cantora, compositora e letrista italiana. Já lançou dois álbuns, escreveu e executou ao vivo as músicas para uma peça teatral de Patroni Griffi e tem actuado muito na Itália e no estrangeiro. Una Persona é o seu primeiro trabalho como encenadora.

\section{REFERÊNCIAS BIBLIOGRÁFICAS}

CAPRA, Fritjof (1989) O Tao da Física: Uma Exploração dos Paralelos entre a Física Moderna e o Misticismo Oriental, trad. Maria José Quelhas Dias e José Carlos Almeida, Lisboa, Presença.

FRANCAVILLA, Roberto (2007), «Sotto a questa realtà. Temas pessoanos nas novelas de Pirandello», ensaio inserido na publicação Luigi Pirandello e a recep̧̧ão da sua obra em Portugal, coord. e trad. Rita Marnoto, Coimbra, Instituto de Estudos Italianos da Faculdade de Letras da Universidade de Coimbra.

LANCAstre, Maria José de (2006), Con un sogno nel bagaglio. Un viaggio di Pirandello in Portogallo, Palermo, Sellerio Editore.

PESSOA, Fernando (1993a), «O Guardador de Rebanhos. VIII - Num meio-dia de fim de Primavera» in Alberto Caeiro, Poemas de Alberto Caeiro, nota explicativa e notas de João Gaspar Simões e Luiz de Montalvor. Lisboa, Ática.

- (1993b), «Passagem das Horas» in Álvaro de Campos, Livro de Versos, edição crítica, introdução, transcrição, organização e notas de Teresa Rita Lopes, Lisboa, Estampa.

- (1990), Livro do Desassossego, vol. I, organização e fixação de inéditos de Teresa Sobral Cunha, Coimbra, Presença.

- (1982), Livro do Desassossego por Bernardo Soares, vol. I, recolha e transcrição dos textos de Maria Aliete Galhoz e Teresa Sobral Cunha, prefácio e organização de Jacinto do Prado Coelho, Lisboa, Ática.

- (1944), Poesias de Álvaro de Campos, nota editorial e notas de João Gaspar Simões e Luiz de Montalvor, Lisboa, Ática.

- (1942), «Autopsicografia» in Fernando Pessoa, Poesias, nota explicativa de João Gaspar Simões e Luiz de Montalvor, Lisboa, Ática.

PIRANDElLo, Luigi (2019), Um, nenhum e cem mil, trad. Francisco Degani, Nova Alexandria, e-book.

SERRÃo, Alice (2013), Prefácio, in Luigi Pirandello, Fuori di Chiave, Milão, AlboVersorio. 